\title{
La génesis ibérica del moderno poder naval
}

\author{
The Iberian Genesis of Modern Sea Power
}

\section{MANUEL VILA GONZÁLEZ}

\author{
Newtesol SL, España
}

RESUMEN: En las postrimerías del siglo XV surgió de la mano de los dos pueblos ibéricos atlánticos una revolucionaria aproximación al uso en beneficio propio del mar, caracterizada por tener que enfrentarse al reto de la navegación oceánica y de la exploración de nuevas tierras, algo jamás siquiera concebido con anterioridad.

Como ya había ocurrido en otras etapas históricas con otros protagonistas, la principal motivación para lanzarse al mar fue económica. Sin embargo, la escala geográfica del empeño en esta ocasión dio lugar a una nueva era, caracterizada tanto por un acelerado desarrollo científico como por una globalización del comercio, de la política, de la tecnología y de la cultura (el lenguaje, la educación y el cristianismo).

Portugal conquistó los océanos con el ánimo de establecer una red de enclaves comerciales, creando el molde de lo que desde entonces se ha considerado el lógico proceder de las potencias marítimas, empeñadas en moverse con libertad por los mares que unen las colonias con la metrópoli. De esa guisa, lo que desde hace apenas poco más de un siglo se denomina poder naval no era sino la parte del poder marítimo que se encargaba de proteger el comercio propio de la ambición ajena.

España, sin embargo, acometió una epopeya similar con una mentalidad más territorial (y más patrimonial), debido a la cual los mismos océanos pasaron a ser considerados parte integrante de las posesiones monárquicas como vínculo que unía las distintas partes del reino. Esa asunción engendró un concepto nuevo de poder naval, por el que en tiempo de paz complementaba al poder marítimo, que se convertía en tributario del primero en caso de conflicto bélico.

Lo que los tratadistas clásicos anglosajones (Alfred T. Mahan y Julian S. Corbett, en particular) describieron como poder marítimo y naval al estudiar la historia basándose en fuentes documentales británicas no es más que la trasposición de los principios que rigieron la constitución del Portugal renacentista en una talasocracia de ámbito planetario.

El caso español es mucho más complejo, pues no solo fue igualmente ignorado en los estudios histórico-estratégicos tardo-decimonónicos y posteriores (no solo anglosajones, lo que es aún más inexplicable), sino que se mantiene en la bruma de lo inexplorado al no haber tenido continuidad histórica reconocida, lo que ha contribuido a impedir una comprensión adecuada de la dimensión histórica del éxito (por su resiliencia, durabilidad, prosperidad...) del "imperio" de la Monarquía Hispánica.

PALABRAS ClAVE: Poder naval, Estrategia naval, Potencia marítima, Modelo español, Portugal. 
ABSTRACT: At the end of the 15th century, a revolutionary approach to the use of the sea for its own benefit emerged from the two Atlantic Iberian peoples, characterized by having to face the challenge of ocean navigation and the exploration of new lands, something never even conceived previously.

As happened in the previous historical stages with other protagonists, the main motivation to jump into the sea was economic. However, the geographic scale of the endeavor on this occasion ushered in a new era, characterized both by accelerated scientific development and by a globalization of commerce, politics, technology and culture (language, education and Christianity).

Portugal conquered the oceans with the aim of establishing a network of commercial enclaves, creating the mold of what has since been considered the logical procedure for maritime powers in order to move freely through the seas that link the colonies with the metropolis. Accordingly, what for just over a century has been called sea (naval) power was nothing but the part of maritime power that was responsible for protecting its own trade from the ambition of others.

Spain, however, undertook a similar epic with a more territorial (and patrimonial) mentality, due to which the oceans themselves came to be considered an integral part of the crown possessions as a link that united the different parts of the kingdom. That assumption created a new concept of naval power, by which in time of peace it complemented maritime power, which became at the same time a tributary of the former in the event of war.

What the classic Anglo-Saxon writers (Alfred T. Mahan and Julian S. Corbett, in particular) described as maritime and sea power when studying the new history in British documentary sources is nothing more than the transposition of the principles that governed the constitution of Renaissance Portugal in a thalassocracy of planetary scope.

The Spanish case is much more complex, since it was not only equally ignored in latenineteenth-century and later historical-strategic studies (not only Anglo-Saxon, which is even more inexplicable), but it remains in the mist of the unexplored by not having had recognized historical continuity, which has contributed to preventing an adequate understanding of the historical dimension of the success (due to its resilience, durability, prosperity...) of the "empire" of the Hispanic Monarchy.

KEYWORDS: Sea power, Naval strategy, Maritime power, Spanish pattern, Portugal.

Recibido: 15 de septiembre de 2020. Aceptado: 11 de octubre de 2020.

Revista de Estudios en Seguridad Internacional, Vol. 6, No. 2, (2020), pp. 235-252. http://www.seguridadinternacional.es/revista/

ISSN: 2444-6157. DOI: http://dx.doi.org/10.18847/1.12.13 


\section{INTRODUCCIÓN}

Asentada como está la idea de que los países que han escrito la historia o son potencias navales o lo son continentales, nos surge la duda de si esa clarificadora simplificación explica bien el papel en la evolución del concierto internacional de todas cuantas han sido potencias marítimas en general, y de las dos naciones ibéricas en particular.

Además, a la luz de la obra de los muchos autores que cogieron el testigo de Alfred T. Mahan (pionero difusor del concepto) en el estudio de las características del poder naval a partir de un análisis histórico, cabe preguntarse si cuantas crónicas navales se escribieron con esas premisas responden a las pautas esperadas tanto en el asombroso caso portugués, como en el de la talasocracia universal en la que la Monarquía Hispánica devino en la Edad Moderna.

Quizá un repaso a las peculiaridades de la exitosa conquista de los mares por ambos reinos nos permita esbozar alguna interesante aplicación en el entorno geopolítico del siglo XXI.

\section{PODER MARÍTIMO Y PODER NAVAL}

Los pueblos antiguos más osados se lanzaron al mar para pescar y para comerciar con lejanos reinos, lo que les trajo prosperidad, pero despertó las más bajas pasiones de algunos de sus vecinos. Surgió así la piratería y en consecuencia la necesidad de defender el incipiente tráfico marítimo mediante el combate, incluso en tierras enemigas si llegaba a ser preciso.

Los fenicios (y a su estela los griegos y los cartagineses) desarrollaron las bases, ya milenarias, del poder marítimo, concebido éste como el conjunto de los recursos de un príncipe o de un estado dedicados al aprovechamiento (económico) del mar. Los pueblos que en la Edad Media, en la Moderna o incluso en la Contemporánea se han adentrado en la mar, lo han hecho siguiendo ese antiguo patrón.

El choque de intereses comerciales siempre ha derivado en la dedicación de muchos de esos recursos, ocasionalmente, para la guerra. Esa necesidad dio origen al poder naval, destinado a garantizar el mantenimiento del comercio y por lo tanto la supervivencia del poder marítimo, del que se ha considerado tradicionalmente una parte importantísima.

Sin embargo, en 1492 apareció un fenómeno inédito de la mano de los Reyes Católicos: la España del Nuevo Mundo; con ella se configuró un entramado que en unas pocas décadas convirtió en ofensa territorial cualquier conflicto marítimo comercial.

Nació así un poder naval especial, que lejos de tener que ser considerado una parte constituyente del poder marítimo, como suele, se convirtió en la razón de ser de todo marino, de todo puerto y atarazana, de todo barco y de tan copiosa parte del ejército como fuera necesaria para llenarlos todos. Es decir, se convirtió en el único tipo de poder de un estado sobra las olas del mar en caso de guerra, haciendo del poder marítimo previo a esa situación una parte más, siquiera auxiliar, del verdadero poder naval.

Así pues, de acuerdo con la tradición española, poder marítimo y poder naval se suceden según las naciones disfruten de paz o estén en estado de guerra. En ausencia de conflicto el poder naval se reduce a unos pocos barcos dedicados a evitarlo, mediante su continua instrucción y su presencia allí donde se les tenga que mostrar para atemperar ánimos. Es una parte reducida de la acción de un estado en la mar (o poder marítimo), que en el siglo XXI engloba además el transporte marítimo y el comercio internacional, 
la navegación deportiva, la construcción naval, la infraestructura portuaria, las zonas de generación energética, la investigación oceanográfica, la pesca, el turismo, las playas, la explotación de los recursos energéticos o minerales submarinos, la protección del ecosistema y del patrimonio sumergido o la seguridad ante el contrabando, la piratería, el terrorismo, la inmigración ilegal y el narcotráfico, por citar los más significativos, todo lo cual debería agruparse en un ministerio al efecto por mor de la mejor concepción y desarrollo de una estrategia marítima...

En caso de guerra, sin embargo, el poder naval lo ocupa todo, convirtiéndose el poder marítimo descrito en parte auxiliar del anterior, como de hecho lo fue en ese tipo de eventualidad durante los tres siglos en los que el cetro del Rey de España y el tridente de Neptuno fueron la misma cosa.

\section{EL NACIMIENTO DEL PODER NAVAL MODERNO}

Los autores anglosajones, y por seguir sus aguas gran parte de los del mundo, han tendido a considerar las guerras anglo-holandesas del tercer cuarto del siglo XVII como el inicio de la época de la navegación a vela en la guerra naval y a ésta como el origen de lo que concibieron como "poder naval" a finales del siglo XIX y comienzos del siglo XX (ver Referencias), tal como convenía en su momento al devenir de sus naciones y guiados por la historiografía angloparlante inevitablemente a su alcance.

Se ignoran así (¿deliberadamente en algún caso o por simple ignorancia histórica?) los dos siglos anteriores desde que los portugueses desafiaron al Mar Tenebroso y comenzaron a explorar la costa atlántica africana primero y la ruta hacia la India bordeando el continente después (Boxer, 2001), a raíz de la expansión otomana y la consiguiente interrupción del tradicional canal de suministro de las especias a Europa.

Los castellanos no tardaron en competir en el empeño, una vez finalizada la conquista de Granada. En 1492 se inició así una nueva era con la expedición hacia poniente de Cristóbal Colón, Juan de la Cosa y los hermanos Pinzón.

Así como la conquista de Constantinopla en 1453 simboliza el final de la Edad Media, el descubrimiento de América es el principal hito fundacional de la Edad Moderna, no solo en la mar. Supuso el banderazo de salida a la "mundialización", el momento en el que las diversas culturas se vieron condenadas al encuentro, con la mar como protagonista.

Con la llegada de los portugueses a la India comandados por Vasco de Gama en 1498, se completa el grueso del esfuerzo luso por sortear las rutas terrestres centroasiáticas, que en las siguientes décadas se extiende hacia levante camino de las Islas Molucas, mientras los castellanos conquistan el Nuevo Mundo, sus imperios y a sus gentes, acabándose por atrever a navegar por el Océano Pacífico.

Todo ese gran abrazo al planeta se trató de un movimiento unidireccional, eso sí, pues fueron las naciones más desarrolladas (las europeas en general y las ibéricas en particular) quienes tomaron la iniciativa, mediante el uso inteligente y centralizado de los recursos marítimos del reino con el fin de establecerse en lejanas costas primero, de promover el monopolio mercantil de determinados bienes, de mantener a salvo su comercio frente a toda amenaza y de derrotar al adversario, llegado el caso, si el conflicto era ineludible, que todo ello se puede entender como incipiente proto-poder naval al alba del siglo XVI.

La génesis del poder naval moderno es, pues, ibérica. Se despliega en los océanos con dos rumbos opuestos (hacia levante Portugal y hacia poniente Castilla) y con conceptos 
estratégicos muy diferentes, tanto en su compromiso con los territorios (y los pueblos) conquistados, como en la propia concepción de lo que el poder naval significaba.

\section{EL CAMBIO DE PARADIGMA MARÍTIMO RENACENTISTA}

La nueva situación que se abrió paso en torno a 1500 supuso un claro cambio de paradigma respecto a lo que había sido durante los siglos previos la utilización del mar para la práctica comercial y el designio político. La construcción del poder marítimo y naval de los dos pueblos ibéricos tuvo muchas cosas en común, características nunca vistas con anterioridad, que configuran la nueva era.

En primer lugar, se forjó una nueva aproximación a lo marítimo, mediante la exploración de océanos hasta entonces ignotos, el descubrimiento de nuevas tierras, el contacto con nuevas civilizaciones y el establecimiento de novedosas rutas que llevasen por otros derroteros al origen de las preciadas especias que la caída del Imperio Romano de Oriente había puesto en manos turcas.

Consecuentemente cambió la escala geográfica en un grado de magnitud y con ello toda idea preconcebida (medieval) sobre la acción del hombre en la mar se convirtió en obsoleta, pues las singladuras se transformaron en travesías y el cabotaje en epopeya transoceánica.

Además, se enriqueció la naturaleza del comercio, pues la carga de vinos, lanas o telas y aún especias se complementó con nuevos productos naturales, artículos de lujo y plata (en lo que puede considerarse, a su vez, un cambio de escala económico), motivo por el que los ocasionales piratas tornaron en flotas corsarias con respaldo más o menos encubierto de los príncipes rivales.

Por otro lado, para poder afrontar técnicamente por vez primera el reto de adentrarse en los océanos, los castellanos y los lusos profesionalizaron la navegación perfeccionando la cartografía, estableciendo instituciones como la Casa de Contratación y escuelas de formación de pilotos en Sevilla o en Lisboa y desarrollando nuevos instrumentos y tipologías de nave a partir de la carabela y de la nao, capaces de cruzar el océano y transportar las riquezas de allende los mares.

Finalmente, como consecuencia de la necesidad de defenderse ante la rapiña de los reinos rivales, atónitos ante el desarrollo económico, tecnológico, social y político que se desplegaba ante sus ojos, los pueblos ibéricos generalizaron el uso de la artillería abordo acabando por dar forma al galeón, primer buque de guerra oceánico propiamente dicho, con el que ya en el último tercio del siglo XVI dio comienzo la verdadera Edad Moderna de la guerra naval, muy bien ejemplarizada en la conquista de las islas Azores acometida por Álvaro de Bazán.

Esa rápida evolución requirió la creación de nuevas instituciones que controlasen y regulasen la acelerada expansión y derivó en la constitución de un nuevo "arte de marear", que según su origen se desplegó con distintos matices para alcanzar lo que más tarde se denominaría el dominio de los mares, a través de dos modelos distintos de comportamiento estratégico y del ejercicio del poder naval.

\section{EL MODELO PORTUGUÉS DE PODER MARÍTIMO Y NAVAL}

Los marinos lusos exploraron nuevas rutas y conquistaron una serie de plazas geográficamente seleccionadas para asegurar la seguridad del transporte marítimo en 
estrechos y zonas de arribada y de transacción con los poderes locales allí donde pudiese haber un interés económico. La prioridad era el comercio, con la consiguiente generación de riqueza en la metrópoli.

$\mathrm{Su}$ idea fue crear un entramado mercantil que controlase el comercio mundial de las especias, y que por lo tanto se extendiese desde Lisboa hasta los confines de Asia (la actual Indonesia e incluso China). El uso de la fuerza solo se hacía necesario para la conquista (eventualmente) de los enclaves elegidos, para mantener alejados a aquellos que quisieran romper el monopolio, para "convencer" a los poderes locales de que cooperasen y comerciasen, teniendo que lidiar con la defensa de sus plazas fuertes distribuidas por medio mundo y de sus líneas de navegación, en lo que se convirtió en el principal cometido de su estrategia y poder naval: la protección de su tráfico marítimo, convirtiéndose en "propietarios" del nuevo espacio marítimo (Duarte, 2010: 69).

De alguna forma, Portugal replicó lo que en la antigüedad habían hecho los fenicios, multiplicando enormemente, eso sí, el tamaño de la proeza. No hizo sino seguir el impulso surgido siglos antes en las repúblicas italianas, "sin más" (nada menos) que incorporar la exploración y el salto a lo desconocido a la ecuación medieval.

Cabe considerar que el poder naval del reino se convirtió en una parte importante de su poder marítimo (aquella que le permitía defenderse y sobrevivir ante los embates violentos de los adversarios) lo que permitía extender los tentáculos de éste (y a través de él de los intereses nacionales), por medio mundo.

Portugal devino en la primera mitad del siglo XVI, de esa forma, en la quintaesencia de lo que se ha dado en llamar potencia marítima (Castex, 1993), creando el modelo tradicional de aproximación al mar que las naciones de alma mercantil observaron a lo largo de los siguientes siglos, y de esa forma desarrollando las pautas a seguir para el establecimiento de un imperio colonial y supeditando la existencia de una estrategia (y de un poder) naval al designio económico y al poder marítimo que debía proteger.

\section{LA PERVIVENCIA SECULAR DEL MODELO PORTUGUÉS}

Al modelo luso consolidado en el siglo XVI se apuntaron los holandeses y los ingleses más de una centuria después.

Los primeros disputaron exitosamente plaza a plaza muchas de las posesiones portuguesas durante la guerra de los ochenta años (Monteiro, 2010), toda vez que esa red colonial acabó estando bajo la corona de Madrid (lo que les procuró a los neerlandeses una clara justificación), que el lobby lusitano impidió (o al menos limitó) la presencia de armadas castellanas en los territorios del Índico (donde de tanta ayuda hubiesen servido, como de hecho demostraron en varias ocasiones en las cercanas Filipinas), y que la solidez del imperio americano español convertía a los territorios portugueses en presa más fácil.

Supieron los neerlandeses, además, refinar el modelo adoptado hasta el extremo de que el peso de su poder marítimo (y naval) lo detentaron las dos "compañías" creadas ad hoc: la VOC (Compañía de las Indias Orientales, fundada en 1602) y la WIC (Indias Occidentales, 1621), en lo que constituye la máxima expresión del carácter mercantilista del poder marítimo y de la subordinación del poder naval al mismo.

Los ingleses, por su lado, que contaban con su propia Compañía de las Indias Orientales (EIC, establecida en 1600), consiguieron cesiones de Lisboa mediado el siglo XVII a cambio de su ayuda a la causa por la recuperación de su independencia, y 
combatieron a los holandeses en el tercer cuarto de dicha centuria por tres veces para poder hacerse con parte de lo que tan afanosamente habían arrebatado éstos a Portugal.

Cuando a finales del siglo XIX y comienzos del XX los primeros pensadores específicamente navales (Colomb, Mahan o Corbett), bucearon en la Historia para entender las constantes que determinan el éxito de la política y de la acción de las naciones en la mar, lo hicieron con historiografía británica y por lo tanto analizaron un relato doblemente parcial, tanto por la subjetividad de la fuente como en el carácter incompleto de la realidad descrita. El resultado es una visión del poder naval que es fiel reflejo de la revolución renacentista que Portugal puso en marcha, y de la que sin embargo ninguno de esos extraordinarios trabajos es consciente de ser plenamente tributaria.

\section{LA POTENCIA MARÍTIMA EN LA MAR}

Entendemos como potencia marítima al país que por su configuración geográfica presume de esa condición, como puede ser una isla-nación, un archipiélago o en determinadas condiciones una península (o incluso parte de ella sin fronteras físicas con un potencial enemigo), con fuerza económica y demográfica suficiente para sostener una importante marina militar que le permita, en la tradición del pensamiento naval, luchar para adquirir "el dominio del mar", y por lo tanto para mantener abiertas y a su servicio las comunicaciones marítimas con objeto de garantizar su tráfico, impedir el del enemigo o eventualmente desplazar contingentes terrestres para el apoyo a sus causas o a las de sus aliados.

En esas circunstancias, el modelo estratégico naval portugués del Renacimiento ejemplifica muy bien lo que debe hacer una potencia de esas características, hasta el extremo de haberse convertido en el esquema básico sobre el que se han construido la mayor parte de los esfuerzos que se han sucedido a lo largo de los siglos sucesivos para asegurar el control del mar. Es seguramente la apuesta más efectiva y que mayor rendimiento ofrece si se considera la ratio "fruto obtenido respecto al esfuerzo empeñado por la nación en la mar". Por eso ha sido la forma más imitada por quienes han ansiado conquistar el mundo a través de los mares.

Todo ello ha provocado que sea la principal (casi única) inspiración de quienes desarrollaron al alba del siglo XX teorías sobre la guerra y el poder naval, aunque en su momento ignorasen el origen luso del modelo, probablemente más que por mala fe por un desconocimiento basado en el origen anglosajón de las fuentes documentales con las que elaboraron sus teorías.

De hecho, cuando Alfred T. Mahan describió los elementos que definen el poder marítimo y naval de una nación en el celebérrimo capítulo I de su obra más emblemática (Mahan, 1890: 25-89), parece que pensaba en el Portugal al que estamos haciendo referencia, que disponía entonces de una larga costa en relación a su tamaño, de una población eminentemente costera, de una flota mercante descomunal, de un tráfico comercial intenso, de importantes y recogidos puertos nacionales, de bases de apoyo en el exterior, de una armada que protegía todos esos intereses, de una cultura marítima natural y de gobernantes con la mentalidad adecuada (hasta el extremo de ser la Casa de Avis reinante la principal impulsora de la actividad marítima). 
A pesar de obedecer a los mismos impulsos iniciales, como es sabido, pero en claro contraste con el "modelo colonial" luso, la expansión hispana no se limitó a comerciar desde plazas fortificadas emplazadas en lugares geoestratégicos, sino que convirtió los nuevos territorios conquistados en parte integrante del reino y a sus gentes en nuevos súbditos del rey.

La estrategia naval española, por paradójico que pueda parecer, era "territorial”, pues el Rey Católico pretendía extender sus dominios incorporando las nuevas tierras y a sus gentes, en lo que acabarían administrándose como virreinatos, capitanías o audiencias, sumando así a los inmensos desafíos geográficos, científicos y defensivos, el reto moral, legal y filosófico que supuso la incorporación de las nuevas almas, pronto transformado en un desafío social, confesional y educativo (a todos los niveles), satisfactoriamente superado.

El poder naval hispano, en consecuencia, respondía a las necesidades que emanaban de esa condición y de esa voluntad, y no se basó solo en la posesión y mantenimiento de una fuerza naval considerable o al menos mínima, para lo que se requería (Black, 2017) y en cumplir con gran parte de los elementos que preconizan las teorías al uso, derivadas todas ellas de las andanzas que siguieron los pueblos que continuaron (a su costa) con el legado portugués: se debió a la superioridad técnica (como ya hemos visto), táctica (tanto en la marina de vela como en la de remo), operacional (gracias al aparato logístico que el reino era capaz de movilizar, capaz incluso de hacer posible la guerra anfibia) y sobre todo estratégica, de los hombres que tuvieron el deber de hacer patente ese poder y usarlo en beneficio de España.

La estrategia naval hispana impulsó el descubrimiento, exploración y conquista de las nuevas rutas y regiones; aun así, no quedó supeditada como consecuencia al comercio oceánico, sino que se extendió tanto a la defensa territorial avanzada en la mar, ayudando a convertir en la medida de lo posible el reino (particularmente la metrópoli) en un bastión inexpugnable, como al suministro de tropas y pertrechos para mantener intacto el reino y a la protección de los derechos de explotación de los recursos propios.

La Monarquía Hispánica tuvo una visión patrimonial no solo de los territorios descubiertos y conquistados, sino incluso de los océanos que los conectaron con Europa, lo que condicionó su mentalidad naval, abocada al más exacerbado pragmatismo a la hora de contemplar en caso de guerra las escuadras como la herramienta idónea para proyectar su inmenso poder sobre la tierra, fuera propia o ajena, lo que es sin duda la impronta más característica de la estrategia y del poder naval de la España "imperial", que siempre ha formado parte del ADN de una Armada en la que lo que modernamente se denominan operaciones conjuntas, fueron durante siglos práctica habitual en las campañas hispanas.

Carlos I, además, creó en 1537 lo que hoy día es la infantería de marina, incorporando tropa específicamente adaptada a la tripulación de galeras, naos y galeones para el manejo de las armas de fuego, la "profesionalización" de los abordajes y el desembarco ofensivo, que gracias a D. Álvaro de Bazán alcanzó en 1583 la excelencia con el asalto anfibio a la isla Tercera, que configuró para siempre ese tipo de operaciones tal como las conocemos hoy, y que quiso replicar en Inglaterra cuando Felipe II le pidió consejo para acabar con su injerencia en Flandes y su corso en el Caribe.

En aquella época se generalizó la protección de los puertos estratégicos (incluso en el Nuevo Mundo) mediante fortificaciones artilladas de traza italiana y la asignación de guarniciones y milicias locales de apoyo, con la intención de convertir el suelo patrio en un santuario, para lo que se dispuso así mismo de la ayuda adicional de una miríada de 
armadas o escuadras adscritas a determinados entornos geográficos y de sistemas de observación y alerta en las costas más expuestas.

También se acabaron de establecer las nuevas líneas transoceánicas de comunicación, particularmente la ruta entre Manila y Acapulco en el Pacífico y la Carrera de Indias en el Atlántico, iniciativas que resultaron especialmente exitosas durante los más de dos siglos que permanecieron imbatibles en la práctica, a pesar de todas las tribulaciones bélicas, meteorológicas, sanitarias, piráticas y de cualquier otro tipo que tuvieron lugar a lo largo de ese largo periodo.

\section{CARACTERÍSTICAS INÉDITAS DEL PODER NAVAL HISPÁNICO}

En 1580 se alcanzó el máximo apogeo del Rey Prudente, consumada la anexión de Portugal a su corona y firmada la paz con la Sublime Puerta que en la práctica fijaba las fronteras marítimas entre el Islam y el Cristianismo. A partir de entonces, quizá porque ya no quedaba mucho mundo de interés por conquistar ("el mundo ya no era suficiente"), la política de expansión de la monarquía ejercida hasta la fecha con mayor o menor entusiasmo se tornó en estrategia defensiva, preocupada mayormente por conservar todo cuanto en ese cénit poseía.

Y así, el sistema naval español, armado ya con las herramientas y la mentalidad adecuadas para lograrlo, mantuvo el grueso del imperio incólume durante las siguientes seis o siete generaciones, elevando a diez la duración de su imperio. Lo hizo gracias por un lado al esfuerzo por mantener el territorio propio a salvo de toda guerra en la medida de lo posible (tanto blindándolo con infraestructuras defensivas y con armadas locales, como llevando la guerra al territorio enemigo) y debido por otro al empeño por mantener el vínculo marítimo entre los diversos espacios geográficos del reino (Borreguero, 2010: 101), unidos comercial, miliar y humanamente sin mácula durante alrededor de tres siglos.

No parece que en lo tocante a la prioridad por proteger el tráfico mercante difiera mucho este nuevo modelo del portugués. Pero lo cierto es que la primacía de la conservación de la integridad territorial a la que la protección del vínculo marítimo se supedita como imprescindible condición, otorga un sentido diferente al valor de la marina, que no solo ha de defender la metrópoli llegado el caso (Mola y Martínez, 2012: 121142), sino que da el mismo valor a otras regiones de la Monarquía donde establece sus diversas fuerzas navales (armadas de Flandes, de Barlovento, del Mar del Sur, escuadras del Cantábrico, de Portugal, del Estrecho, de galeras de España, de Sicilia, de Génova o de Nápoles, de Filipinas...), con un carácter escalable que las permitía agruparse, junto con las naves mercantes que se precisaran, en grandes flotas que permitieran llevar la guerra a la costa del adversario.

Por todo ello, se da la paradójica circunstancia de que el poder naval no solo no forma parte en el caso español del poder marítimo, sino que son realidades paralelas durante los periodos de paz, para convertirse llegada la guerra (casi siempre defensiva a lo largo de los tres siglos de inmensa talasocracia hispánica), en la única expresión de la acción del reino en la mar, de la que el poder marítimo pasa a formar parte a su servicio, sea con el uso de sus puertos e infraestructuras, bien convirtiendo sus medios en refuerzo de las escuadras (las propias naos del siglo XVI son un ejemplo inmejorable), o bien ayudando al transporte de socorros, ejércitos o vituallas en los diversos teatros.

Salvo la protección al comercio, significativa pero no exclusivamente mediante su sistema de flotas (O’Donnell, 2012), toda operación que concebía la estrategia naval 
hispana de la época estaba pensada para la protección directa de los intereses vitales en tierra, así como para la proyección del poder militar sobre nuestros enemigos en su territorio desde la mar, con intención evidente de influir en el devenir político (histórico) de los acontecimientos.

Esa paradójica mentalidad naval territorial va más allá de la imprescindible coordinación entre la marina y el ejército (o incluso de la subordinación de la primera al segundo), por el hecho de que sea "casi imposible que una guerra se pueda decidir únicamente por la acción naval” (Corbett, 1911: 13). Es sin duda la más acusada característica del poder naval hispano y lo que le distingue del de todas las demás naciones. Hasta el extremo de que la protección al tráfico marítimo no dejaba de ser la salvaguarda del vínculo oceánico que unía las distintas partes de la Monarquía Hispánica.

Parece una réplica, a mucha mayor escala, del logro romano, donde llegó a no darse opción a poder naval ajeno. Así fue de hecho en el Mar Caribe, centro de muchos de los intentos foráneos para establecer una base local que permitiese la piratería y el corso en mejores condiciones, en el Océano Atlántico, o en nada menos que el Pacífico (auténtico mare nostrum), gigantescos espacios todos ellos para uso y disfrute del Rey Católico, donde las potencias rivales solo se atrevían a interferir picoteando con sus destacamentos corsarios: franceses primero, durante el reinado de Carlos I; ingleses después, fastidiando a Felipe II, y holandeses más tarde, incumpliendo sistemáticamente su tregua con Felipe III. Su hijo Felipe IV pudo haber presumido de soportar las embestidas de todos ellos, si bien los galos, que se acabaron convirtiendo en los principales adversarios durante el reinado de Carlos II, tuvieron el detalle de limitarse a hostigar en los mares europeos llegado el siglo XVII.

\section{LA PERVERSIÓN HISPANA FRENTE A LA LÓGICA DE MAHAN}

Cuando uno concibe el poder naval con las pautas establecidas por Mahan y enriquecidas por Corbett, y tiene acceso a esa parte de la historia marítima mundial que le ha sido sutilmente ocultada, puede descubrir y entender sin esfuerzo el papel pionero de la extensa nómina de grandes marinos lusos durante el mandato de la Casa de Avis (Rodrigues, 2010). Portugal creó un mundo nuevo, más grande, más interconectado y a la postre, más rico. Dio a luz a los primeros pasos de la globalización (Nascimento e Devezas, 2007). Y quienes siguieron su modelo iluminaron al marino norteamericano con sus hazañas navales para que dejara constancia de cuantos elementos habían permitido a unos y otros construir sus imperios de los mares.

Sin embargo, la gigantesca contribución de España a la Historia a través, precisamente, de su odisea marítima, no puede comprenderse del todo bajo la óptica del análisis convencional desarrollado por los estrategas navales más conocidos, donde no cabe ni la definitoria territorialidad explicada en el epígrafe anterior, ni la forma en la que la Monarquía Hispánica concebía la estrategia naval.

A este último respecto, cabe señalar que mientras para Mahan la estrategia naval tiene como objeto fundar, sostener y aumentar el poder naval (tal como la define en el último párrafo del primer capítulo de "La Influencia del Poder Naval en la Historia"), la praxis de Madrid demuestra lo contrario cuando permite a España consolidarse por tres siglos como la talasocracia más grande que haya visto la Humanidad: es el poder naval quien ha de servir a la estrategia naval y no al revés. Es la orquesta la que se somete a la partitura y no la partitura la que se subordina a la orquesta, por lo que la corona española siempre tuvo cuidado de dimensionar los medios a sus necesidades defensivas procurando no ir 
mucho más allá. Y a la vista está que esa política (solo en apariencia cicatera) le fue de gran utilidad para conservar el imperio del mar durante siglos y permitir el desarrollo económico y cultural en todos sus dominios.

Así pues, es imposible aprehender el modelo español descrito mediante el uso de los términos clásicos que emanan del pensamiento naval anglosajón desarrollado entre finales del siglo XIX y comienzos del XX, tanto por la territorialidad de la estrategia naval de la Monarquía Hispánica, como por su preeminencia sobre el poder naval, a su servicio siempre. Si por la teoría estratégica naval clásica fuera, el imperio español no hubiese podido existir. De hecho, no hay más que leer a Mahan para corroborarlo.

Por ese motivo la principal tesis al uso del pensador estadounidense (a saber, la prioridad de la batalla decisiva entre flotas), nunca fue de aplicación significativa en el caso de España, que solo recurrió al combate cuando no le quedó más remedio (aun siendo la potencia dominante en muchas de las fases de esa historia) y siempre como ineludible herramienta para conseguir un fin más importante, fuera el socorro a una plaza asediada o la defensa del tráfico marítimo, por ejemplo.

Evalúese la distribución y composición de las armadas del Rey Católico durante la dinastía de los Austria y se podrá comprender mejor lo que significa que el poder naval (tal como es concebido el concepto desde hace poco más de un siglo), bailase al son de la estrategia naval de la corte. Y después recuérdense los hechos (y los no-hechos) de armas de esos siglos en términos de defensa de sus puertos y sus costas, de la seguridad de las rutas comerciales y el éxito de las flotas del tesoro y de los socorros emprendidos, del daño procurado al comercio enemigo, de las conquistas acometidas mediante desembarcos y operaciones anfibias, de los ataques a los nidos de corsarios, del bloqueo a las costas enemigas o de la protección de los recursos naturales en aguas propias, para así poder comprender por qué el Imperio de los Océanos hispano pervivió sin apreciable mácula durante más de trescientos años... en los que, por cierto, también tuvieron lugar batallas navales decisivas, en muchos casos como fruto inevitable de campañas $u$ operaciones de índole ajena a la mera eliminación de la escuadra enemiga.

\section{LA POTENCIA HEGEMÓNICA EN LA MAR}

Es posible que la mentalidad hispana, más que simultánea consecutivamente ofensiva (exploración, conquista, ocupación...) y defensiva (conservación del patrimonio heredado) proviniera de una baja Edad Media en la que la principal política de los reinos peninsulares consistió en la reconquista y repoblación de la tierra musulmana. Aragón ya se había zambullido en el Mediterráneo con Jaime I cuando acabó lindando al sur solo con la cristiana Castilla. Y ésta dejó de atisbar sus costas por la popa tan pronto como tomó Granada, en una dinámica que, al margen de la odisea americana, conquistó el Reino de Nápoles (a manos del Gran Capitán y su revolución militar) y varias plazas estratégicas del Norte de África gracias al impulso del Cardenal Cisneros y a las armas de Pedro Navarro, fiel escudero de Fernández de Córdoba en su epopeya napolitana.

Ese espíritu de conquista aún latente devino en un modelo muy complejo que aspiraba a la hegemonía territorial y al monopolio comercial a lo largo y ancho de los océanos.

No hay una etiqueta adecuada para clasificar un poder naval así, y por eso creemos que más que considerar a la Monarquía Hispánica o bien una potencia naval o bien una continental, deberíamos hablar de una "potencia hegemónica", como de hecho lo fue, en distinto grado y en diversos ámbitos geográficos, durante los tres siglos que van de Fernando de Aragón (Fernando V de Castilla) a Carlos IV. 
Hay que retrotraerse a Roma para poder entender el proyecto imperial de los Austria; también en la mar, pues no hay moderno parangón a tan enorme y prolongado alarde de poder naval. Si acaso Gran Bretaña en el siglo XIX, tras una centuria previa de transición $\mathrm{y}$ aprendizaje, en la que fue abandonando el modelo portugués y adoptando el tan incomprendido modelo hispánico de poder naval, si bien con una particularidad: nunca fue capaz de proyectar una fuerza de combate (en una costa defendida por un ejército moderno) comparable a la que durante la dinastía de los Austria representaron los tercios (o a la que en la época romana caracterizaron las legiones).

A la incipiente versión británica en el siglo XIX del modelo hispánico de poder naval le faltó el punch anfibio, solo recuperado en la Segunda Guerra Mundial por quienes se consideraron sus herederos. Y es que EE.UU. ha sido desde entonces lo más parecido a una potencia hegemónica. Bien se podía haber convertido en una en toda su extensión sin más que haber seguido la política expansionista que mostró hasta esa fecha, pero al margen de las circunstancias históricas del momento, nada proclives a ese tipo de anexiones, en sus genes tenía más influencia del modelo luso heredado de su sangre anglosajona que del español, a pesar de que la mayor parte de su territorio llegó a formar parte de la Monarquía Hispánica, legado del que triste e incomprensiblemente, y para su desgracia, ha renegado siempre de la mano de sus élites gobernantes y educativas.

\section{EL NACIMIENTO DEL CONTRAPODER NAVAL}

Quizá lo más increíble de la odisea marítima que protagonizaron España y Portugal fue que lo hicieran de mutuo acuerdo en virtud del tratado de Tordesillas en fecha tan temprana como 1494, complementado con el de Zaragoza en 1526. De esa forma evitaron todo riesgo de conflicto bélico y pudieron centrar sus energías en el desarrollo de sus dominios a lo largo y ancho del planeta.

Una vez tomaron la delantera e incrementaron su poder marítimo hasta cotas pocas décadas antes inconcebibles, el primer sentimiento que surgió en el seno de todas las cancillerías rivales fue de envidia, y a pesar de que las naciones ibéricas se olvidaron de enfrentarse a quienes no se cruzaban en su camino, hubo naciones que se juramentaron contra el excesivo poder de quienes por no repartir el pastel consideraban sus enemigos (Münkler, 2020: 75-85), permitiendo (alentando incluso) la actividad corsaria de sus súbditos para socavar en lo posible ese poder y no verse directamente comprometidos por ello.

El caso más inmediato fue el de la Francia de Francisco I, que comenzó a hostigar a los españoles tan pronto como Hernán Cortés conquistó el Imperio Azteca, como airada reacción al incremento del poder de su vecino del sur, que en cuestión de apenas unos años, y contra toda lógica, impidió el sueño francés de alzarse como la potencia dominante en Europa, al establecer su supremacía política, rodear físicamente con sus territorios o los de sus aliados el suelo galo y fijar los sólidos cimientos de un monopolio comercial con el Nuevo Mundo que duraría siglos (Bordejé, 1985).

Francia dispuso de una marina digna (con la que también tuvo sus más y sus menos con su vecino del norte, si bien por motivos diferentes), aunque insuficiente para revocar "el testamento de Adán", por lo que a menudo empleó métodos que carecían de toda dignidad, en especial contra el tráfico transatlántico hispano; era además, seguramente, su manera de alejar un peligro adicional (desde la mar) en un país que estaba literalmente rodeado de enemigos gracias a la visión estratégica de Fernando el Católico. Desde ese 
punto de vista, el recurso al corso (paradigmáticamente ofensivo, desde un punto de vista táctico y operativo), no fue sino una medida estratégicamente defensiva.

Álvaro de Bazán el Viejo acabó con el incordio naval galo dando cuenta del grueso de la flota francesa, a la que sorprendió en plena "faena" en Muros (1543), en la que fue la primera experiencia bélica de su primogénito. Tras aquella batalla, Francia desapareció en la práctica de los mares durante casi cuatro décadas (Fernández Duro, 1972), y solo su molesta incursión en la Florida supuso algún quebradero de cabeza para España, resuelto en cualquier caso por Menéndez de Avilés (uno de los grandes cerebros a los que se debe la puesta en marcha de la Carrera de Indias) de forma expeditiva y con gran visión estratégica.

La acumulación exagerada de poder en manos de Felipe II tras la unificación ibérica provocó la oficiosa toma de partido por parte de Francia a favor del prior de Crato, huido pretendiente a la corona lusa, y de nuevo fue expulsada de los mares en 1582 (esta vez durante medio siglo) por el primer Marqués de Santa Cruz en la batalla de San Miguel.

En el último tercio del siglo, la Inglaterra de Isabel I tomó el relevo de Francia y los "perros de la reina" se atrevieron incluso a cruzar el océano con escuadras de cierta entidad para atacar las costas del Nuevo Mundo en busca de tesoros que les fueron siempre esquivos.

Las provincias rebeldes de Flandes, a su vez, recurrieron inicialmente a métodos "híbridos" (en la terminología bélica del siglo XXI) para luchar con sus "mendigos del mar" contra quienes consideraban sus enemigos por razones solo formalmente religiosas.

Aunque el poder naval moderno se desarrolló como tal en el Océano Atlántico, la reacción de Argel al ímpetu conquistador hispano replicó las mismas pautas corsarias al amparo del Imperio Otomano, no muy lejos de lo que los Caballeros de San Juan hacían con la vista puesta en tan poderoso enemigo después de que éste les expulsara de Rodas y Carlos I les cediera el uso de Malta, ayudando desde entonces a la Monarquía Hispánica de los Austria a combatir al Islam.

En suma, la configuración del moderno poder marítimo (y naval) que protagonizaron España y Portugal en el siglo XVI, dio lugar a un "contrapoder marítimo y naval" patrocinado oficiosamente por los estados rivales y basado en las técnicas habituales de la piratería, esto es, el asalto al tráfico marítimo y el ataque a determinados puertos enemigos en incursiones cortoplacistas con el ánimo de robar cuanto hubiese de valor.

\section{EL SER O NO SER DEL CONTRAPODER NAVAL}

Salvo para quienes disponían de cierta herencia marítima medieval (caso de Génova y Venecia o en cierto modo de la Sublime Puerta), el origen del poder marítimo de gran parte de los reinos que se adentran en la mar en el siglo XVI, en muchos casos resentidos por la excesiva fuerza de la católica España, es muy poco edificante para lo que son los estándares morales del siglo XXI (y aún de la época...).

Algunos de aquellos principados acabaron convirtiéndose en contrapoderes consolidados como "repúblicas corsarias", caso de Argel (pronto imitado por otras ciudades-estado del Norte de África).

Sin embargo, ya en el siglo XVII, tanto los Países Bajos como Inglaterra supieron adoptar la estrategia que Portugal les había mostrado para convertirse en poderes navales al uso, de forma que su violenta praxis más que centrarse en las naves que surcaban los 
mares en el entorno de las aguas metropolitanas de llegada, se focalizó en el ataque a los enclaves geoestratégicos de las potencias entonces consolidadas, con letales efectos para el imperio marítimo luso (Monteiro, 2010), y sin muchas consecuencias para el hispano, mucho más sólido, seguramente por la tipología de conquista que ya hemos señalado, por la fortaleza de sus flotas, de sus armadas y de sus escuadras y por la profesionalidad de sus marinos y de sus soldados embarcados, vital para la táctica que entonces se imponía en la batalla por las carencias de la artillería y las características de los galeones.

Esa evolución "natural" desde el corso en alta mar (escuela de combate naval), al ataque sorpresa a los puertos enemigos (escuela de navegación oceánica), a la sustracción de las bases de operaciones portuguesas (escuela de conquista), y a la organización de convoyes comerciales (escuela de escolta al tráfico), constituye por un lado el paradójico resultado del contrapoder naval que tiene éxito, y por otro la génesis del poder naval que describen los clásicos a partir del momento en el que la "guerra galana" (en terminología española de la época), es decir, el duelo artillero de suyo inconcluso, sustituye al abordaje como el paradigma del combate naval, poniendo fin a la era de los galeones mediado el siglo XVII.

De esta forma, los alumnos más aventajados del contrapoder naval (siempre reacios a acercarse demasiado a los galeones hispanos) acabaron convirtiéndose en potencias marítimas y navales, y pasaron pronto a tener que proteger su propio comercio.

\section{LA POTENCIA CONTINENTAL EN LA MAR}

Las que se denominan "potencias continentales" son naciones a las que no les va en principio la vida en la mar, porque tienen al enemigo apostado en su frontera común, pero temen que sus costas se conviertan en indefensa retaguardia en un momento dado y saben que una marina de cierta enjundia puede proporcionarles cierta disuasión frente a los países de condición marítima con quienes puedan mantener potenciales disputas e incluso procurarles aliados en ese ámbito para mejor posicionamiento de cara a sus enemigos continentales. Inversamente, sus enemigos marítimos pueden aliarse con sus vecinos continentales para fijar su esfuerzo defensivo.

De una u otra forma, parece claro que aquellas naciones que responden a este concepto tradicional, pueden no obstante convertirse en poderosos actores en los océanos si disponen de los recursos y de la voluntad para poner en marcha (y sostener) una marina adecuada (Gorshkov, 1978), siempre que sean capaces de desarrollar una estrategia naval adaptada a sus necesidades, y a pesar, incluso, de la carencia de algunos de los elementos constitutivos del poder naval de los que hemos hablado.

Con esos mimbres, la forma más inmediata que tiene una nación de estas características para desplegar cualquier ambición naval es estratégicamente defensiva, con la vista puesta tanto en la protección del tráfico marítimo de su incumbencia como en la salvaguardia de sus costas.

Sin embargo, el corso es más efectivo como herramienta defensiva disuasoria, pues obliga a la potencia marítima a defenderse, evitando que tome la iniciativa. Solo una reacción propia de otra potencia continental colindante o de una potencia hegemónica podría acabar de raíz con esa praxis, mediante la conquista de las bases de partida, al estilo de lo hecho por Carlos I en Túnez en 1535, Francia en Dunkerque (aliada con Inglaterra) provocando el final de su guerra con España en 1659, o como concibió hacer Felipe II en la Empresa de Inglaterra en 1588. Pero esa solución no es en general factible cuando las bases están en suelo de la propia potencia continental. 
Esta forma de entender la guerra en la mar volvió a verse durante la guerra fría en la Unión Soviética, cuya marina de guerra priorizó el arma submarina (negadora de la libertad de uso de las líneas marítimas por naturaleza), al igual que hiciera Alemania en las dos guerras mundiales, siguiendo la tradición corsaria de la Francia atlántica de la primera mitad del siglo XVI, del Dunkerque del XVII (bajo bandera alternativamente española y gala), de los argelinos a la sombra del Imperio Otomano durante más de dos siglos, de los caballeros de Malta mientras ayudaron a la Monarquía Hispánica de los Austria a combatir al infiel, o de los súbditos de Isabel I de Inglaterra.

Se da la circunstancia de que incluso una potencia hegemónica (o incluso únicamente marítima) puede hacer uso del corso sin descuidar sus otras obligaciones navales. Lo hizo la Monarquía Hispánica en el siglo XVII, primero para combatir a Argel con sus propios métodos por iniciativa del Duque de Osuna, virrey de Sicilia y más tarde de Nápoles durante el reinado de Felipe III; lo volvió a hacer con mucho éxito tras habilitar el acceso al puerto de Dukerque cuando reinaba Felipe IV, para ahogar así la economía de las siete provincias rebeldes de Flandes, de Inglaterra o de Francia, alternativamente o la vez, según la época. Y siguió haciéndolo Carlos II para socavar la fuerza gala desde las provincias vascas en el último tercio del siglo.

EE.UU. también ejerció el corso masivo mediante su arma submarina en la guerra del Pacífico contra Japón, buscando (y logrando) el colapso económico del enemigo.

$\mathrm{Si}$ ha habido un intento de teorizar sobre este modelo (siquiera parcialmente), combinando la defensa del territorio propio con la última tecnología y con el ataque al tráfico enemigo, se trata sin duda del protagonizado por la Jeune École, preludio ineludible de toda aproximación defensiva a la mar en el siglo XX, tal como demostraron germanos y soviéticos, según se ha mencionado.

\section{EL PODER NAVAL EN LA PRÓXIMA GENERACIÓN}

En la actualidad estamos viviendo la expansión naval de la República Popular China, lo que constituye el mayor desafío al status quo marítimo (y no solo marítimo) desde el final de la Guerra Fría, hace una generación.

Pasada la época en la que se limitó a pensar en su marina como un instrumento meramente defensivo y lo suficientemente fuerte ya como para aspirar a algo más que a convertirse en una "república corsaria", cabría pensar que un país eminentemente continental y bloqueable por mar por rivales indisimulados de configuración eminentemente marítima, adoptaría una estrategia naval basada en la combinación de una fuerza de acción marítima que asegurase la defensa de sus costas con una flota respetable que sirviera para mostrar el pabellón y amagar frente a rivales más poderosos, al estilo de la Alemania de la primera mitad del siglo XX, de la URSS en la Guerra Fría o de Francia en muchas de sus etapas históricas.

Pero no es así... China parece haber elegido ser la Portugal renacentista (o la Holanda barroca) del siglo XXI: está construyendo una flota de vocación hemisférica y sentando las bases para crear un imperio colonial de acuerdo con el modelo luso en todo el Océano Índico, mientras se apropia a su vez de sus mares adyacentes para impedir el acceso a esa área de interés de otras marinas y desarrolla su comercio marítimo hasta niveles casi inconcebibles hace una generación.

La búsqueda (o compra) de alianzas y recursos naturales que ha guiado la política exterior china en ese último periodo ha estado muy bien engranada con su expansión 
marítima y naval, especialmente indisimuladas en lo que va de siglo, lo que ha provocado la reacción de los países del entorno, impulsando un incremento notable en las ambiciones navales de Japón, de Corea del Sur, de Australia y de la India, especialmente.

Rusia es otra nación que quiere hacer patente el aumento de su poder naval en los últimos años, dedicando ingentes recursos a reconstruir su armada tras el descalabro naval que supuso la desintegración de la URSS como consecuencia de su derrota en la Guerra Fría. El creciente protagonismo internacional de China es sin duda el mejor acicate para perseverar en tal empeño, si bien su enfoque antioccidental, tan caduco y tan ajeno al común sentir en Europa, es de difícil comprensión a este lado del continente, donde se hubiese esperado más una política de creciente entendimiento, colaboración e integración que una de confrontación y de provocación gratuitas.

Sorprende la relativa inacción de EE.UU., que pese a todos los debates al respecto, no acaba por definir una variación significativa de la política naval que tanto réditos le ha venido dando desde el final de la SGM, a pesar de que ya no es el primer importador de hidrocarburos, ni el centro del comercio marítimo mundial, ni el mayor exportador de bienes del mundo. Todos esos papeles, con el mar como protagonista, se los ha arrebatado China, que incapaz de absorber internamente su producción y dependiente como lo es del suministro energético exterior, sin embargo, presenta debilidades que intenta combatir con una marina poderosa, y que sus rivales estratégicos deberían saber explotar desarrollando capacidades que puedan asfixiar su economía llegado el caso, sea mediante un eventual bloqueo (lo que cada vez será más difícil), o sea mediante el uso "industrial" del corso tal como hoy se concibe, para lo que el número de submarinos debería aumentarse considerablemente, mientras se conserva la capacidad de destrucción de las bases de apoyo que va sembrando por medio mundo.

Finalmente, indigna observar la parálisis europea ante lo que está pasando en el mundo, como si no fuera con ella. Los gobiernos de los países de la UE han estado en lo que va de siglo más preocupados en mantenerse en el poder pese a las cuitas internas que en poner en marcha una política de estado que preserve el bienestar alcanzado frente al avance económico y la política internacional eventualmente lesiva de naciones y sociedades que no respetan los valores fundamentales de los que gozamos en Europa (libertad de expresión o de culto, democracia, estado de derecho, igualdad...).

Cuando los "dragones asiáticos" (primero Japón y luego Corea del Sur, Singapur o Taiwan) sorprendían con su crecimiento a finales del siglo XX, nadie estaba preocupado desde un punto de vista estratégico, porque eran naciones democráticas que jugaban con las reglas de la economía de mercado. Eso también ha cambiado y por eso merita una reacción conjunta, ponderada e inteligente, pragmática y conciliadora pero preventiva, de todas esas naciones que se comprometieron en 2014 a dedicar a su presupuesto de Defensa un mínimo del $2 \%$ de su PIB en el horizonte de diez años, y que a apenas tres del final de periodo han hecho una clara dejación de sus obligaciones.

Los países de Europa Occidental deben asumir ya la necesidad de multiplicar, por un lado, sus medios navales y de integrar por otro hasta el límite de lo posible (su propia soberanía nacional) sus armadas, compartiendo información, intercambiando personal, operando combinadamente, etc.

\section{CONCLUSIÓN}

A partir del Renacimiento se puede hablar de poder naval moderno (debido a un cambio de escala en el ámbito marítimo de un orden de magnitud), cuyo despliegue, sazonado 
con una nueva estrategia naval globalizada, ejecutan España y Portugal al alimón cuando se lanzan al océano hasta entonces inexplorado.

El modelo portugués de poder naval es colonial, basado en el comercio desde una red de plazas bien fortificadas ubicadas en lugares geoestratégicos. Es un modelo imitado y suplantado (usurpado) por holandeses primero e ingleses más adelante. Configura lo que se dio en llamar potencia marítima.

La Monarquía Hispánica no parece responder a ninguno de los mutuamente excluyentes estereotipos de potencia marítima o continental a los que nos acostumbró la historiografía del siglo XX. El modelo español es de naturaleza hegemónica, domina la tierra y el mar, y no se entiende lo uno sin lo otro; de hecho, cuando no se pudo disponer del vínculo por mar, se separó la tierra, como ocurrió tras la Guerra de Sucesión con los dominios europeos (en Flandes y en Italia), o tras Guerra de la Independencia en los americanos. Solo el Imperio Romano podía compararse con la Monarquía Hispánica y solo la Gran Bretaña victoriana pudo aspirar después a equipararse a la España filipina.

En contra de lo que se ha venido considerando la visión clásica desarrollada a partir de la historia naval británica, en el modelo hispánico el poder naval no es una parte del poder marítimo (sino que éste se integra en el primero en caso de conflicto), y en cualquier caso queda subordinado a una estrategia naval que paradójicamente es territorial.

La potencia continental puede aspirar a tener algo que decir en el concierto de las naciones más allá de su influencia decisiva por tierra en el devenir histórico de sus vecinos. Es un esfuerzo meritorio de quien no se juega la supervivencia como estado en la mar. El corso, que fue la primera aproximación al mar de las potencias rivales de las ibéricas en la Edad Moderna (algunas de las cuales se acabaron convirtiendo en potencias marítimas), es el elemento disuasorio más destacado de las potencias continentales, si bien no es exclusivo de ellas.

La URSS retomó el camino del esfuerzo naval de una potencia eminentemente continental que ya había mostrado Alemania en la primera mitad del siglo XX; China, en la actualidad, sin embargo, sigue el manual para convertirse en potencia marítima, cambiando de esa forma el mundo que conocemos, ante lo que es inexplicable la inacción occidental (y en particular la europea).

NOTA SOBRE EL AUTOR:

Manuel Vila González. Empresario, ingeniero industrial y analista naval, asiduo colaborador de Cuadernos de Pensamiento Naval, publicación del Centro de Pensamiento Naval de la Escuela de Guerra Naval de la Armada en Madrid y de la Revista General de Marina, editada por el Cuartel General de la Armada. Correo electrónico: manuelvilaglez@gmail.com

\section{REFERENCIAS}

Black, Jeremy (2017), "Spanish military power in relation with other states: a comparative context" en García Hernán, Enrique y Maffi, Davide (Eds.), Estudios sobre Guerra y Sociedad en la Monarquía Hispánica. Guerra marítima, estrategia, organizaciñon y cultura militar (1500-1700), Valencia: Albatros Ediciones, pp. 355-374.

Bordejé, Fernando (1985), España, poder marítimo y estrategia naval, Madrid: Editorial Naval. 
Borreguero Beltrán, Cristina (2010), "Logros del Imperio Español: el poder militar y diplomático", en García Hernán, David (Ed.), La Historia sin complejos, La nueva visión del Imperio Español, Madrid: Actas Editorial, pp. 99-135.

Boxer, Charles R. (2001), O Imperio Marítimo Português 1415-1825, Lisboa: Edições 70

Castex, Raoul (1993), Strategic Theories - Selections by Eugenia C. Kiesling, Annapolis: Naval Institute Press

Colomb, Philip H. (1895), Naval Warfare, Its Ruling Principles and Practice Historically Treated, London: W.H. Allen \& Co.

Corbett, Julian S. (1911), Principles of Maritime Strategy, London: Longsman, Green \& Co.

Duarte, António P. (2010), "Portugal maior", Limes, Rivista Italiana di Geopolitica, No. 5, pp. 67-74.

Fernández Duro, Cesáreo (1972), Armada Española desde la unión de los reinos de Castilla y de Aragón, Madrid: Museo Naval.

Gorshkov, Sergei G. (1978), The Sea Power of the State, Annapolis: Naval Institute Press.

Mahan, Alfred T. (1890), The Influence of Sea Power upon History 1660-1783, Boston: Little, Brown \& Co.

Mola, Marina A. y Martínez Shaw, Carlos (2012), "Defensa naval de los reinos de Indias”, en O'Donnell, Hugo (Coord.), Historia Militar de España - Edad Moderna Ultramar y la Marina, Madrid: Ediciones del Laberinto, pp. 121-142.

Monteiro, Saturnino (2010), Portuguese Sea Battles - Vol. IV-VI, Lisboa: Saturnino Monteiro.

Münkler, Herfried (2020), Imperios, Madrid: Nola Editores.

Nascimento, Jorge e Devezas, Tessaleno (2007), Portugal, O Pioneiro da Globalização, Lisboa: Centro Atlântico.

O’Donnell, Hugo (2012), "Función militar de las flotas de Indias", en O’Donnell, Hugo (Coord.), Historia Militar de España - Edad Moderna - Ultramar y la Marina, Madrid: Ediciones del Laberinto, pp. 81-119.

Rodrigues Pereira, J. Antonio (2010), Marinha Portuguesa - Nove Séculos de História, Lisboa: Comissão Cultural de Marinha. 